\title{
What shapes local health system actors' thinking and action on social inequalities in health? A meta-ethnography
}

\author{
Naoimh E. McMahon ${ }^{1}$ (D)
}

Accepted: 18 January 2022

(c) The Author(s) 2022

\begin{abstract}
Local health systems are increasingly tasked to play a more central role in driving action to reduce social inequalities in health. Past experience, however, has demonstrated the challenge of reorienting health system actions towards prevention and the wider determinants of health. In this review, I use meta-ethnographic methods to synthesise findings from eleven qualitative research studies that have examined how ambitions to tackle social inequalities in health take shape within local health systems. The resulting line-of-argument illustrates how such inequalities continue to be problematised in narrow and reductionist ways to fit both with pre-existing conceptions of health, and the institutional practices which shape thinking and action. Instances of health system actors adopting a more social view of inequalities, and taking a more active role in influencing the social and structural determinants of health, were attributed to the beliefs and values of system leaders, and their ability to push-back against dominant discourses and institutional norms. This synthesised account provides an additional layer of understanding about the specific challenges experienced by health workforces when tasked to address this complex and enduring problem, and provides essential insights for understanding the success and shortcomings of future cross-sectoral efforts to tackle social inequalities in health.
\end{abstract}

Keywords Social inequalities in health - Social determinants of health · Discourse . Meta-ethnography $\cdot$ Health systems

\section{Introduction}

Social inequalities in health are differences in health outcomes that exist between groups of different socioeconomic position. In contrast to differences that arise due to factors such as ageing or chance, these inequalities are said to be "systematic,

Naoimh E. McMahon

n.mcmahon1@lancaster.ac.uk

1 Division of Health Research, National Institute for Health Research School for Public Health Research (NIHR SPHR), Lancaster University, Lancaster LA1 4YW, UK 
socially produced (and therefore modifiable) and unfair" (Whitehead and Dahlgren 2006). They reflect the conditions in which people are born, grow, live, work, and age; conditions that are in turn shaped by the grossly inequitable distribution of power and resources in society (Marmot et al. 2008). These underlying or 'root' causes of social inequalities in health have, typically, been considered to be beyond the purview of local health systems. However, greater recognition of the financial cost of socioeconomic inequality (Asaria et al. 2016), along with the rising demand on services due to preventable ill-health (National Health Service 2019), has meant that health systems are increasingly mandated to play a more central role in addressing them. For example, in England, it is envisioned that ongoing reforms will enable local health systems to reach beyond traditional health services and work alongside local authorities and voluntary organisations to drive action on the social and economic determinants of health (The King's Fund 2021). Previous research, however, has demonstrated how difficult it is to reorient health system efforts towards more preventative action, and towards tackling the social and structural drivers of inequalities in health (e.g. Blackman et al. 2012; Orton et al. 2011). Current ambitions are also set against an especially challenging backdrop where, after over a decade of austerity and cuts to public services, life expectancy improvements in England have stalled (Marmot et al. 2020a), and widening inequalities are now being further exacerbated by the inequitable impacts of the ongoing Covid-19 pandemic (Marmot et al. 2020b).

Further qualitative research has been conducted in recent years, both in the UK and internationally, to explore how this mandate to tackle health inequalities and their wider determinants takes shape within local health systems. These studies have a particular focus on illuminating how and why individual actors think about, and work to address, health inequalities in the ways that they do (e.g. general practitioners, public health officers, health system leaders etc.). In this review, I draw on meta-ethnographic methods to synthesise findings from these investigations into a novel, overarching, and theoretically informed 'line-of-argument' about what sustains the gap between the recognised need for greater preventative action on the underlying causes of inequalities, and what ultimately gets implemented in practice. This synthesised account provides an additional layer of insight about the specific challenges experienced by health system workforces when tasked to address this extremely complex and enduring problem. These insights which will be essential to understanding the future success and shortcomings of reforms, both in the UK and internationally, that are designed to enable cross-sectoral and collaborative action to reduce social inequalities in health.

\section{Methods}

The review is reported in line with the eMERGe guidance for reporting meta-ethnography (France et al. 2019a), which aligns to Noblit and Hare's 7 stages (Noblit and Hare 1988): (i) getting started, (ii) deciding what is relevant, (iii) reading the studies, (iv) determining how the studies are related, (v) translating the studies into each other, (vi) synthesising translations, and (vii) expressing the synthesis (see 
Appendix A). As the details of the aims and rationale for the review have already been described (Stage 1), this section begins with Stage 2: Deciding what is relevant.

\section{Deciding what is relevant}

Stage 2 involved extensive reading of potentially relevant studies to familiarise myself with the volume of available literature, and the different ways in which authors have tried to unpack the puzzle of why health system actions often diverge from stated intentions to reduce inequalities through action on their underlying causes. Studies were deemed to be relevant to the review if they: (i) provided indepth explanatory accounts about how health system actors come to both think about, and act upon, social inequalities in health, (ii) were published in English, and (iii) in a peer-reviewed journal. Studies which focused solely on inequalities in access to healthcare were excluded.

Searches were performed at two time points. Four electronic databases were initially searched from their inception to the 11th of December 2018 (Web of Science including MEDLINE; PsycINFO; EMBASE and CINAHL). The full search strategy was rerun on the 22nd of May 2020. The search string was devised using target papers, and included a combination of terms for inequalities in health and qualitative research: ("health inequalit*" or "health equit*" or "social determinants of health") AND (qualitative or interview* or focus group* or discourse* or framing* or construct* or perception* or perspective* or understand* or discussion*). Hand-searching of reference lists and citation tracking was also carried out for all included articles. Retrieved citations were compiled into a single EndNote® library, screened on title and abstract, and for those deemed to be potentially relevant, full texts were retrieved and assessed for eligibility. The flow of papers through this process is shown in Fig. 1, and an overview of the included studies is provided in Table 1 (organised chronologically by year of data collection). A list of the excluded citations with reasons is provided in Appendix B in the online supplement.

Although a significant number of qualitative studies were identified during the searches, a large majority of these either examined the implementation of specific initiatives to reduce social inequalities in health (e.g. area-based initiatives; Health in All Policies) or were found not to provide explanatory insights about health system actors' perspectives and practices. While there were no limits on country or setting, the inclusion criteria, and perhaps also how the review question was framed, resulted in a set of studies from English speaking nations which were most recognisably situated within a social inequalities in health or social determinants of health research tradition. Three of the included studies centred on a single professional group (e.g. general practitioners), with the remainder including participants from a mix of professions or spanning front-line, operational, and strategic leadership roles.

\section{Reading and data extraction}

Stage 3 involved the repeated reading of included studies to become familiar with their content, and to make a note of author interpretations relevant to the aims of the 


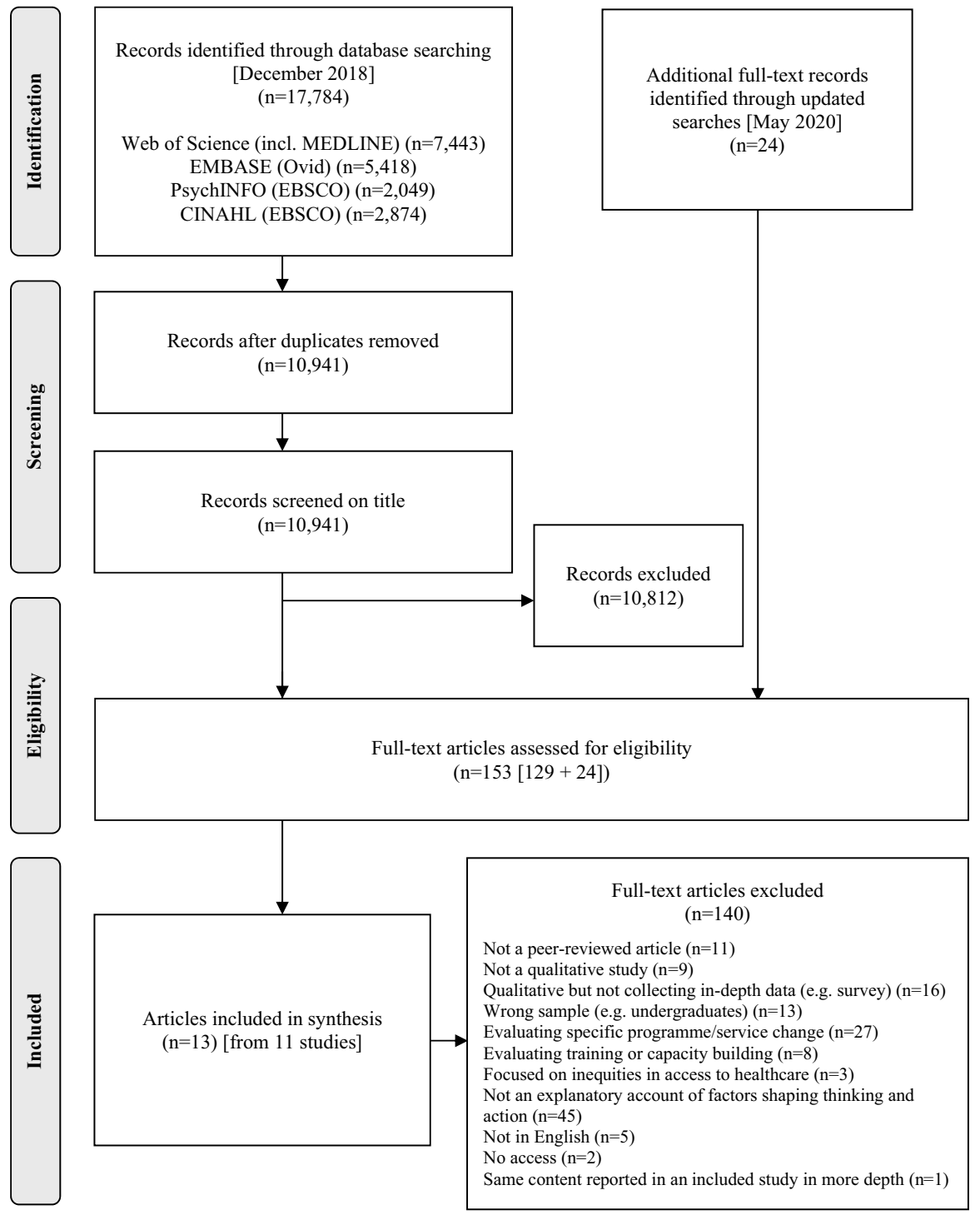

Fig. 1 PRISMA flow diagram

review. In meta-ethnography, a distinction is often made between three levels of interpretation. Participants' own views and perspectives are treated as '1st order' constructs. Study authors' interpretations of these 1st order constructs are considered '2nd order' constructs. Lastly, '3rd order' constructs refer to the new insights and interpretations generated by review authors through the process of synthesising the included studies (Malpass et al. 2009). Akin to the experience of others (for example Atkins et al. 2008; Smith and Anderson 2017), I found it difficult to differentiate between 1st and 


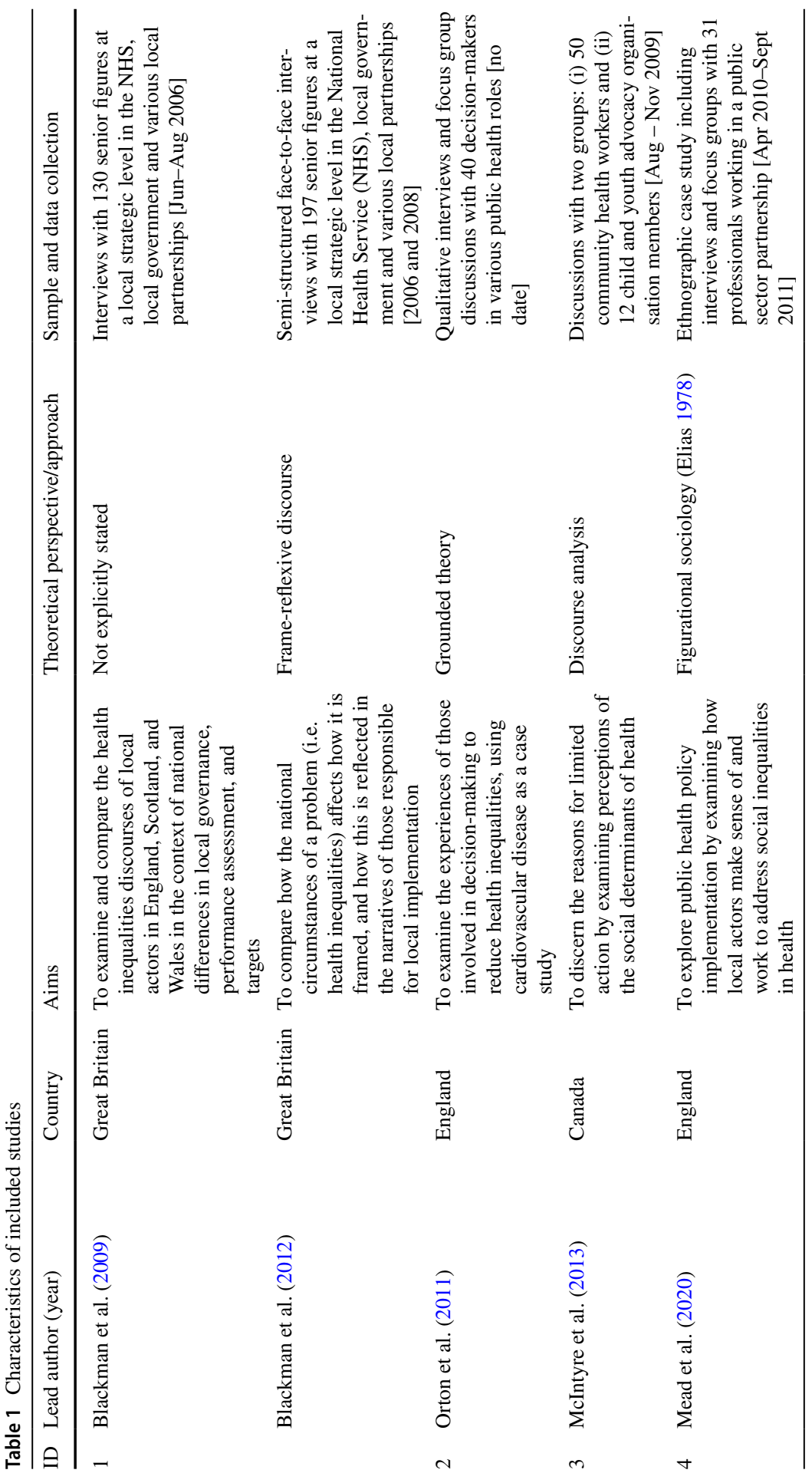




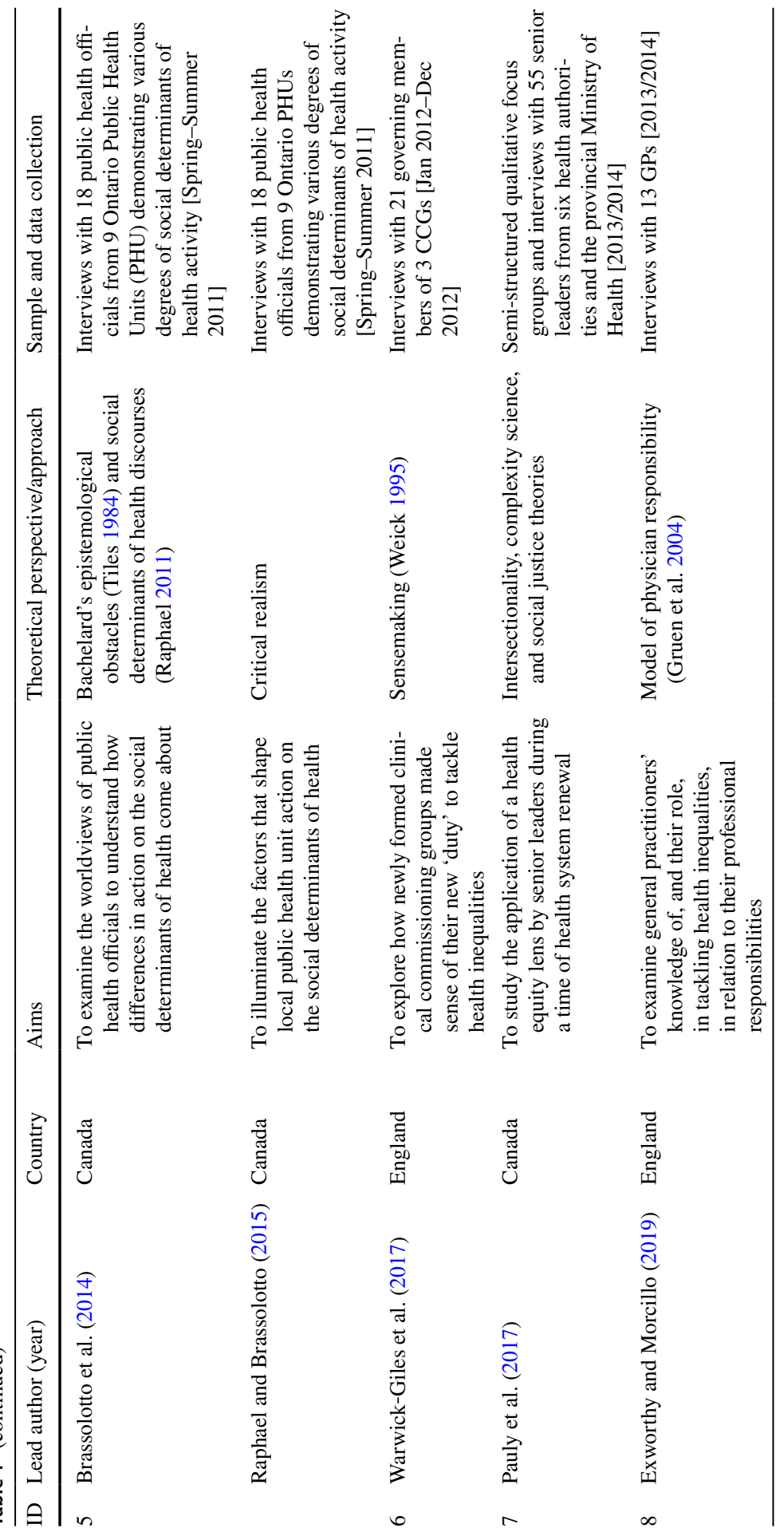

站。 


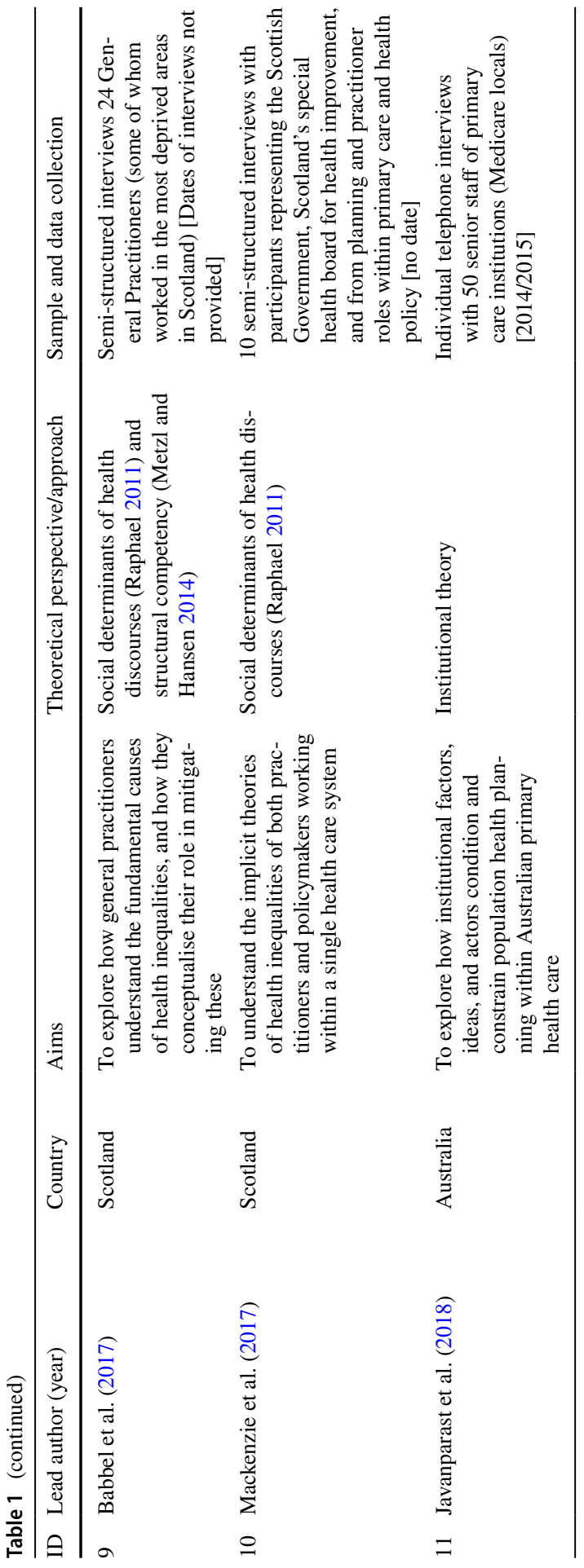


2nd order constructs in the published articles, as participant quotes were predominantly used to evidence authors' own interpretations. As such, all data extracted at this stage were treated as 2nd order constructs. Further contextual details were also collected using a bespoke data extraction form (e.g. author details, year of publication, country, study aims, sample, method of data collection, and the approach to analysis). In light of the difficulty of differentiating a poor-quality study from a poorly reported study (Atkins et al. 2008), a formal approach to quality appraisal was not used. However, only studies which had undergone peer-review were eligible for inclusion.

\section{Analysis and synthesis}

Stage 4 of a meta-ethnography involves looking across the 2nd order constructs for each study to establish how the studies are related to each other. This process was supported by developing a table in Microsoft Word® with the included articles forming the first row, and the 2 nd order constructs forming the columns. In a process described as 'translation' (Noblit and Hare 1988), I worked systematically through each 2nd order construct to examine how it might be related to those identified in the other studies. It became evident during this process that the articles could be grouped into two clusters, those which focused more on the influence of organisational factors, and those which emphasised the intrinsic characteristics of individual health system actors. In line with the guidance from France et al. (2019b), I first carried out a reciprocal translation for the 2 nd order constructs of each cluster (Stage 5), before bringing these together and synthesising into a 'line-of-argument', or a 'new storyline', about what the studies say (Stage 6). As Thorne et al. (2004) describes, this process is based on the premise 'that often people study different aspects of phenomena', and that by arranging the translated 2nd order constructs in a particular way, it is 'allows us to construct an argument about what the set of ethnographies say'.

After some trial and error, I found that arranging the study insights into a storyline underpinned by Foucauldian ideas provided the most useful and meaningful account of the data. Taking guidance from the structured approaches to Foucauldian-inspired analysis offered by Bacchi (2009) and Willig (2013), the line-of-argument starts by detailing how social inequalities in health tended to be 'problematised' or 'discursively constructed' by participants within the included studies. I then locate these perspectives within the wider discourses from which they arise, and go on to illuminate how such discourses have very real and material effects in terms of constraining how health system actors can both think about, and work to address, social inequalities in health. A Foucauldian perspective proved especially useful in this review because it makes explicit how health system actors are governed by the problems they are tasked to address, and how these problems are shaped by powerful and influential discourses operating both within and outside of the health system. 


\section{Findings}

Eleven studies, reported in thirteen published articles, were included in the metaethnography (Table 1). The earliest studies were conducted in Great Britain where authors sought to illuminate how the national policy imperative to reduce health inequalities took shape within local health systems between 2006 and 2010 (Blackman et al. 2009; Blackman et al. 2012; Orton et al. 2011). These were followed by a number of qualitative studies in the UK and Canada which specifically set out to illustrate how individual health system actors problematised health inequalities and action on the social determinants of health (McIntyre et al. 2013; Mead et al. 2020; Brassolotto et al. 2014; Raphael and Brassolotto 2015; Pauly et al. 2017; Exworthy and Morcillo 2019; Babbel et al. 2017; Mackenzie et al. 2017). Two additional studies, one from England (Warwick-Giles et al. 2017) and one from Australia (Javanparast et al. 2018) were also included, with each contributing further insights on how health equity objectives were operationalised during more recent health system reforms. There was substantial variation in the level of detail provided in the included studies about how individual participants problematised social inequalities in health. Some provided a quantified breakdown of perspectives, either at the level of the individual practitioner (Babbel et al. 2017), or organisation (Brassolotto et al. 2014), whereas others relied on more high-level generalisations (e.g. Blackman et al. 2009; Blackman et al. 2012; McIntyre et al. 2013). Taken together however, the studies collectively point to the existence of a predominant perspective on social inequalities in health.

\section{A predominant perspective on social inequalities in health}

This predominant perspective was characterised by a concern for the health of specific 'disadvantaged' groups or geographical regions. While instances of participants drawing on 'victim blaming' discourses, or having an expressly negative view of such groups (and their lifestyle 'choices') were rare, health system actors were generally found to hold an 'individualised' understanding of inequalities in health. For example, although they often acknowledged the importance of the social determinants in shaping health outcomes, these determinants were invariably problematised as 'individual risk factors' for health, consequently 'obscuring' their relationship to structural inequality, politics, and policy (Mead et al. 2020; Brassolotto et al. 2014). The result was a tendency for health system actors to focus on activities to increase individual access to, or uptake of, health promoting resources (i.e. healthcare, healthy lifestyles, and the wider determinants of health), rather than questioning or challenging their inequitable distribution. As such, the majority were said to hold a 'reductionist' view of the problem, which failed to account for both the 'complexity' of health inequalities and their 'political roots' (Pauly et al. 2017; McIntyre et al. 2013; Mackenzie et al. 2017). In stark contrast were the minority of study participants who problematised inequalities in terms of a social gradient in health, and who viewed the distribution of the social determinants as indicative of wider 
structural inequality. Thus, rather than a cleaving apart of forces, these individuals were found to explicitly 'tie together' individual health outcomes, the social determinants of health, politics, and policy. While all studies alluded to the importance of individual perspectives, Babbel et al. (2017) and Brassolotto et al. (2014) were most explicit in arguing for the existence of 'clear linkages' between actors' problematisations of health inequalities and perceptions about their own role in taking action. Those who subscribed to narrower versions of the problem were inclined to see tackling wider social forces as 'outside the scope' of their work, in contrast to the minority who felt they were uniquely well-placed, and indeed had a professional responsibility, to try and influence determinants beyond individual encounters.

\section{The role of discourse in sustaining the predominant perspective}

This predominant perspective on social inequalities in health was found to be shaped, and sustained, by powerful and influential discourses operating both within and outside of local health systems. Drawing on the translated 2nd order constructs (Table 2) and key examples from the included articles, the following sections detail the role of discourse in shaping individual conceptions of health, how these tend to align with internal governance arrangements and external pressures on local health systems, and consequently why it proves so difficult for health equity 'counter-discourses' to gain traction in practice.

\section{Biomedical individualism and positivist conceptions of health}

Authors attributed the predominant perspective on social inequalities in health to the influence of biomedical, individualistic, and positivist discourses that are so prominent in Western societies (McIntyre et al. 2013; Mead et al. 2020; Brassolotto et al. 2014; Javanparast et al. 2018). Collectively, these discourses operate to promote a focus on individuals (rather than the contexts and conditions in which they live); to emphasise the importance of individual responsibility for health; and to privilege causal understandings that hinge on direct and observable logics of cause and effect. Brassolotto et al. (2014) were most explicit in deeming the different perspectives of public health unit staff in their study as being 'epistemological' in nature, arguing that it was the different worldviews of participants which served to either exclude, or bring into the frame of understanding, the less visible social and structural forces that drive and sustain inequalities in health. Two studies went a step further in trying to account for why some health system actors, albeit a minority, rejected the dominant discourses to problematise health inequalities through a more 'structural', rather than individualised, lens. The concept of 'exposure' was central to these accounts. Raphael and Brassolotto (2015) highlight how some public health unit staff held a greater awareness and sensitivity towards structural factors because of either 'first-hand' experience of inequalities (e.g. through socioeconomic background, ethnicity), or because they had initially trained in non-medical fields (e.g. social work, political science). In a similar way, Babbel et al. (2017) found that the general practitioners in their study who held more structural perspectives had more 


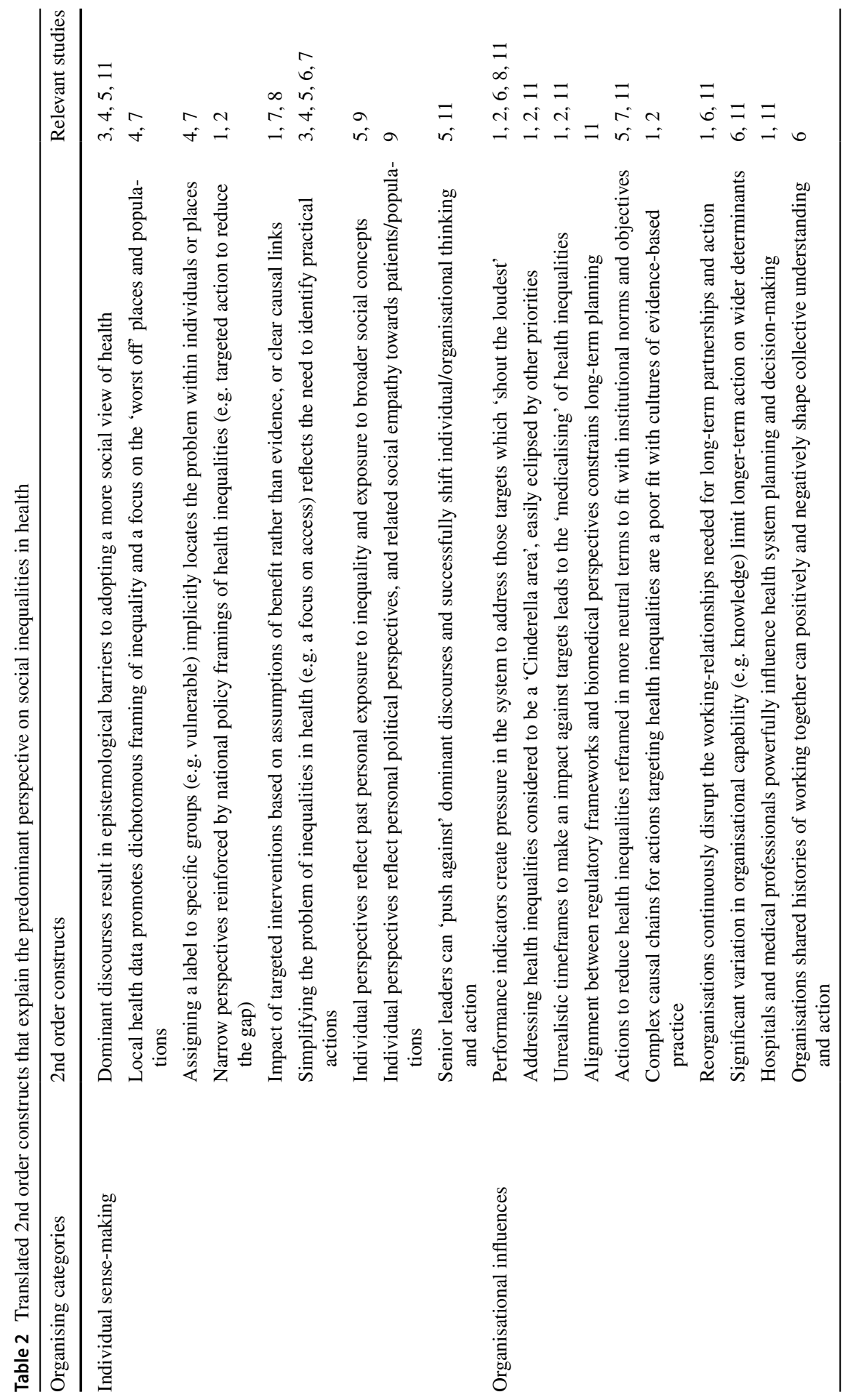




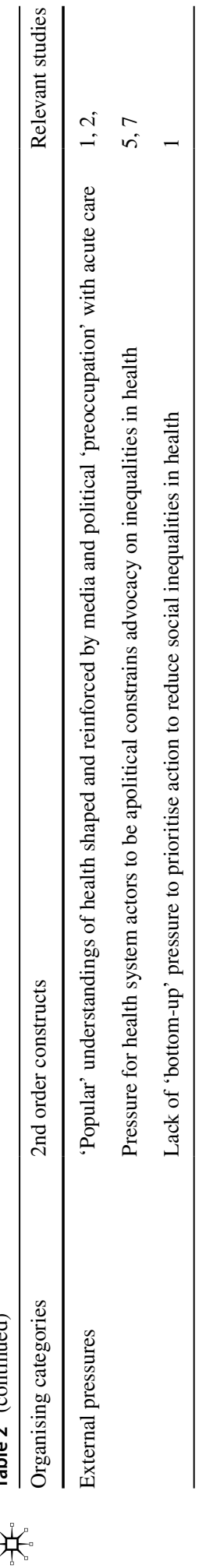


experience of working in areas of severe deprivation, and as a result demonstrated great 'social empathy' towards patients and the wider forces impacting upon their personal circumstances. The authors do note however that the direction of this relationship is unclear and that it may be the case that GPs with a 'particular political perspective' gravitate towards such roles.

\section{Alignment with organisational discourses and external pressures}

Importantly, the predominant perspective on social inequalities in health was also shown to both closely align with, and be further reinforced by, organisational discourses. Firstly, study authors illustrated how the very practice of using epidemiological data to categorise and compare inequalities between population groups and geographical regions (e.g. life expectancy figures), served to unhelpfully promote dichotomous extremes and a focus amongst participants on the 'worst off' groups (Mead et al. 2020). As Pauly et al. (2017) further describe, the prominent practice of assigning a 'label' to populations (e.g. 'at risk', 'vulnerable') further served to position individuals themselves as problematic, rather than the social structures and institutional processes that perpetuate risk and vulnerability. The concern for authors was that the resulting discourses reinforce narrow problematisations of health inequalities; have the potential to further stigmatise particular areas and population groups; and actually, as Blackman et al. (2012) describe, lead to a lack of critical reflection about how targeted interventions will reduce inequalities, beyond an assumption of benefit because they are 'mainly supporting poorer people'.

Secondly, authors pointed to a plethora of governance arrangements stemming from both influential new public management and evidence-based policy and practice discourses, which further served to medicalise and individualise the problem of social inequalities in health within local health systems. For example, in England in 2001, explicit targets were introduced around reducing gaps in life expectancy and infant mortality. While initially not perceived to be a 'high stakes issue' in terms of accountability, increasing pressure to demonstrate rapid improvements against these targets was said to ultimately 'bias' action towards short-term 'quick wins' in the form of targeted pharmacological treatment for 'at risk' population groups (Blackman et al. 2012). Javanparast et al. (2018) have more recently described how long-term planning for action on the social determinants of health was constrained by a complex of funding arrangements, regulatory frameworks, reporting requirements, and timeframes that all aligned with taken-for-granted biomedical definitions of health and the dominant 'curative' paradigm within the Australian primary health care system. A further difficulty that individual actors faced in seeking to 'redress the balance' towards prevention and tackling health inequalities, was the inherently poor fit between interventions targeting the social determinants of health, and organisational imperatives to be able to predict, evidence, and quantify the direct impacts of investment (Orton et al. 2011). Indeed, even in more conducive contexts, where there was a greater recognition of the need to improve living conditions (e.g. Scotland), the challenge of making the 'financial case' for action, within these organisational frameworks, persisted (Blackman et al. 2012). Also highlighted 
were a number of practical constraints which were said to further limit action on the wider determinants of health. These included having the right knowledge and skill sets within local health systems to deliver longer-term cross-sectoral programmes of work (Javanparast et al. 2018), and, most notably in an English context, frequent health system reorganisations which continuously disrupt the working-relationships needed for long-term partnerships and action (Warwick-Giles et al. 2017).

Lastly, studies pointed to an additional layer of alignment between internal organisational discourses and the external pressures which local health systems are under. Blackman et al. (2012), for example, outline how a focus on treatment reflects the 'preoccupation' with hospitals and acute care services amongst the media, elected representatives, and indeed the public. The distinct lack of 'bottom-up' pressure to prioritise health inequalities, coupled with the need for health system actors to be 'apolitical' when publicly advocating for health system or policy change (Raphael and Brassolotto 2015; Pauly et al. 2017) led to a persistent sense that health inequalities would always be easily 'eclipsed' or 'overshadowed' by more 'politically sensitive’ priorities (Blackman et al. 2009).

\section{Challenges in operationalising counter-discourses}

While authors did not explicitly label health equity discourses, or ideas around the social determinants of health, as 'counter-discourses' per se, they are undoubtedly designed to go 'against the grain' (Mead et al. 2020) and challenge dominant ways of thinking and working. There were however extensive difficulties reported by health system actors in actually trying to operationalise these ideas in practice, and not solely due to the challenges set out above. McIntyre et al. (2013), for example, describe how ideas around tackling the root causes of health inequalities (i.e. inequalities in power, money, and resources) were perceived by Canadian community and public health workers to be 'overwhelming', and, in light of the longer-term timeframes for impact, 'offering little' to people dealing day-to-day with populations experiencing inequality. These concerns were not limited to more front-line practitioners but were also expressed by health system leaders who similarly described how health equity and the social determinants of health often appeared in the dialogue 'too big to tackle' (Pauly et al. 2017), further reflecting that it seemed as though 'health equity' had become an 'umbrella term' which had 'momentum', but without the necessary 'clarity' to allow for its practical application in their everyday work. Indeed, even talking about health equity proved a challenge for some participants who felt that, across the health system, there wasn't a shared understanding of the problem, nor a shared language to discuss it (Orton et al. 2011, Pauly et al. 2017). As a result, actors tended to revise their language to ensure that the way in which they framed health equity objectives were more readily accepted within their organisations and more easily understood. Examples included talking about vulnerable populations rather than complex social relations (Pauly et al. 2017), and talking about a 'healthy place to live' rather than the social and structural determinants of health (Raphael and Brassolotto 2015). Authors recognised that this more general process of 'simplifying' the problem of social inequalities in health was a 'rational 
response' and, an arguably inevitable consequence, for health system actors who have little power to influence the wider determinants (Mead et al. 2020). However, there were concerns that the ultimate consequence would be to further legitimise institutions norms (Javanparast et al. 2018), and reinforce the seemingly intractable nature of both health inequalities and wider social injustice (Pauly et al. 2017).

Importantly, despite all of the insights set out above about how powerful discourses constrain thinking and action, there were examples across the studies of individuals and organisations who were able to advocate for a structural perspective on social inequalities in health and enable health system engagement and action on their underlying causes. The fact that these individuals were often working within similar policy contexts, or with similar institutional constraints, led authors to conclude that the distinguishing factors were the ideas and beliefs held by senior staff and leaders who were able to 'push against' institutional discourses, norms, and mandates to promote new ways of thinking and working (Brassolotto et al. 2014; Javanparast et al. 2018). Warwick-Giles et al. (2017), in particular, also highlighted the relational element and how shared histories of success and positive experiences of 'doing things together' in multi-organisational partnerships were essential in enabling collective action on health inequalities.

\section{Discussion}

The purpose of this meta-ethnography was to synthesise qualitative research studies that have explored how ambitions to tackle health inequalities and their wider determinants take shape within local health systems. The included articles had a particular focus on illuminating how and why individual actors think about, and work to address, inequalities in health in the ways that they do. Drawing on a Foucauldian perspective, the resulting line-of-argument illustrates how health system actors are, as Bacchi (2009) would say, governed by 'problematisations'. In particular, it has shown how the problem of social inequalities in health is moulded by powerful and influential discourses to fit both with pre-existing conceptions of health and inequalities, and the institutional practices which delimit what can be thought and done. In this section, I will first discuss how the findings of the meta-ethnography chime with insights generated through qualitative research in national policy settings, before discussing some recent critiques of health equity discourses and where they may be inadvertently contributing to the challenges outlined in the review.

Qualitative research with policy-makers has similarly emphasised the importance of the policy 'problem', and how it is invariably transformed to fit with both dominant discourses, and institutional structures and practices. Akin to the experience within local health systems, Qureshi (2013), for example, has illustrated how the drive for technical, quantifiable, and evidence-based solutions to health inequalities within the English civil service led to a 'shifted conception' of problem. While initially considered in terms of a social gradient that mandated action on the wider determinants of health, the problem, over the course of implementation, was quickly reimagined as 'property' of 'deprived people or communities', and one which could be addressed through an expansion of targeted health improvement interventions. 
Shifting conceptualisations of health inequalities have also been attributed to the more deliberate actions of civil servants who, in contrast to local health system actors, are especially constrained by the immediate political context, and the ideological persuasions of ministers. Drawing on insights from discursive institutionalism, Smith (2014) in particular, has highlighted how the task of 'competitively marketing' evidence and ideas within government led to actions on health inequalities being reframed in ways which were more politically palatable, in line with current policy directions, and, consequently, had the best chance of surviving the policy process. The end result, however, was that more challenging ideas, for example around reducing economic inequality, were significantly downplayed.

More recently, Lynch (2017) has provided a slightly different angle in explaining persistent policy inaction on the underlying causes of health inequalities. Based on qualitative interviews with policy-makers from across four European countries, she explains that the more fundamental issue is the way in which governments have embraced a reframing of social inequality in health terms. This reframing has had profound consequences for what the problem is understood be, where responsibility for action lies, and ultimately how amenable it is to change. As Lynch (2017) describes, a health framing inevitability leads to responsibility being situated within health ministries, where the problem of inequality becomes 'medicalised' by policy actors whose worldviews are more oriented towards individualism and a medical model of health. Importantly, while the 'victim blaming' discourses that Galvin (2002) has previously described were not to fore of studies included in this meta-ethnography, the legacy of emphasising individual responsibility for health and illness clearly does persist amongst health actors, and makes it difficult to move beyond a focus on individuals, to more explicitly consider the social structures and processes sustaining inequality. Smith (2013) has described how these difficulties are further compounded by institutional structures within departments, such as policy 'silos', which effectively serve to 'filter' out evidence and ideas that require cross-departmental working. The result is a focus within health departments on more immediately available levers, such as increasing health promotion activity and equitable access to services (Baum et al. 2013; Qureshi 2013; Smith 2013). Importantly, this challenge to the appropriateness of centring health, and health outcomes, is not limited to national policy settings. Ethnographic research within municipal government departments in Denmark found that a focus on health equity within intersectoral policy making led to the implementation of small-scale health promotion interventions in non-health settings (e.g. schools), rather than more co-ordinated action on the social determinants of health (Holt et al. 2017).

Highlighted in this meta-ethnography, and arguably further contributing to the institutional challenges already described, is the extent to which health equity 'counter-discourses' actually enable health system actors to think about inequalities in a more structural way. Indeed, many of the insights from the studies which focused specifically on actors' perspectives on the social determinants of health, actually reflect critiques that have already been levelled at the model in wider literatures. For example, some authors would suggest that the predominant narrow, and reductionist, perspective is not surprising because the rainbow model itself promotes a focus on single discrete categories of determinants, rather than 
aspects of the political economy and wider social processes that shape their distribution (Hankivsky and Christoffersen 2008; Krieger et al. 2012, Yates-Doerr 2020). To bring about this required shift in attention, Spiegel et al. (2015) have argued from a move away from talking about the social determinants of health, to better understand and theorise the social determination of health. In their recent reflection on 30 years of the rainbow model, Dahlgren and Whitehead (2021) pick up on these critiques and reiterate that, despite its popularity in the health equity field, the model is just a visual representation of the determinants of health, and not the determinants of health inequalities. They describe how latter involves a 'further conceptual leap' to consider different levels of power and resources; different levels of exposures to health hazards; differential impacts of the same exposures; life-course effects; and the social and economic impacts of being sick. As such, they conclude that there is a need to better illustrate these interconnected processes to enable effective action on the root causes of social inequalities in health. In light of the reflections from study participants in this review however, it is important that such resources enable constructive dialogue about tackling these root causes across health and wider local systems, and in a way that empowers and enables people to take action, rather than serving to overwhelming them.

Importantly, questions about the utility and impact of health equity 'counterdiscourses' are not limited to professional groups, but are also increasingly being explored amongst different publics (Smith et al. 2021; Fairbrother et al. 2021; Lundell et al. 2013), with a view to understanding what is needed to generate the grassroots pressure to reduce inequalities which health system actors so often suggest is lacking. A recurrent finding in this research is the paradox between deep and nuanced understandings of the relationship between social inequality and poorer health outcomes, in particular amongst groups most exposed to social injustice, and a reluctance to acknowledge or accept the existence of a social gradient in health (Smith and Anderson 2017). To explain this paradox, authors have critiqued the determinism inherent in health equity discourses which, in relying on models of often unidirectional arrows from macro social structures to individual health outcomes, risk being both stigmatising and disempowering for different population groups (Lundell et al. 2013; Smith and Anderson 2017). This point was central to a recent critique of the social determinants of health where it was argued that the desire to avoid victim blaming within health equity discourses has actually served to downplay the role of individual agency to the point where people are effectively reduced to 'puppets on strings' (Lundberg 2020). These insights, and indeed more recent research with citizen juries in a UK context, point to a challenging balancing act in advancing health equity discourses which can simultaneously counter the problematic tendency for publics to individualise health, but in ways that are neither disempowering nor likely to reinforce prominent fatalistic discourses about the possibility for successfully reducing health inequalities (Smith et al. 2021). 


\section{Conclusion}

As Noblit and Hare (1988) describe, any meta-ethnographic account is but one possible interpretation of the phenomenon being studied and, indeed, the point is not to achieve 'closure', but rather to further enrich and enable discussion on a topic. The line-of-argument presented in this review centres upon the importance of understanding how problems take shape within systems, and illustrates how the problem of social inequalities in health is persistently transformed and reconfigured to fit both with pre-existing narrow and reductionist conceptions of health and inequality, and the institutional practices which constrain thinking and action within local health systems. This finding is especially important in light of current reforms in which local health systems, and their workforces, are increasing being drawn into conversations and planning to tackle social inequalities in health. It will be especially important to capture and understand how these cross-sectoral partnerships negotiate the influence of health systems, and the extent to which system leaders can ensure that narrower and more medicalised notions of health and inequity do not undermine the potential for more transformative action on the underlying causes of social inequalities in health.

Supplementary Information The online version contains supplementary material available at https://doi. org/10.1057/s41285-022-00176-6.

Acknowledgements I would like to thank Professor Caroline Watkins, Professor Mark Gabbay, and Dr Justin Jagosh for their supervisory support when undertaking this work as part of my doctoral studies. Thanks also to Professor Jennie Popay and two reviewers for constructive comments on an earlier version of this manuscript.

Funding This report is independent research funded by the National Institute for Health Research Applied Research Collaboration North West Coast (NIHR ARC NWC). NMcM is currently funded by a National Institute for Health Research School for Public Health Research (NIHR SPHR) Postdoctoral Launching Fellowship. The views expressed in this publication are those of the author and not necessarily those of the National Institute for Health Research or the Department of Health and Social Care.

Data availability The data that supports the findings of this study are available from the author on request.

Open Access This article is licensed under a Creative Commons Attribution 4.0 International License, which permits use, sharing, adaptation, distribution and reproduction in any medium or format, as long as you give appropriate credit to the original author(s) and the source, provide a link to the Creative Commons licence, and indicate if changes were made. The images or other third party material in this article are included in the article's Creative Commons licence, unless indicated otherwise in a credit line to the material. If material is not included in the article's Creative Commons licence and your intended use is not permitted by statutory regulation or exceeds the permitted use, you will need to obtain permission directly from the copyright holder. To view a copy of this licence, visit http://creativecommons.org/licen ses/by/4.0/. 


\section{References}

Asaria, M., T. Doran, and R. Cookson. 2016. The costs of inequality: Whole-population modelling study of lifetime inpatient hospital costs in the English National Health Service by level of neighbourhood deprivation. Journal of Epidemiology and Community Health 70 (10): 990-996.

Atkins, S., S. Lewin, H. Smith, M. Engel, A. Fretheim, and J. Volmink. 2008. Conducting a meta-ethnography of qualitative literature: Lessons learnt. BMC Medical Research Methodology 8: 21.

Babbel, B., M. Mackenzie, A. Hastings, and G. Watt. 2017. How do general practitioners understand health inequalities and do their professional roles offer scope for mitigation? Constructions derived from the deep end of primary care. Critical Public Health 29 (2): 168-180.

Bacchi, C. 2009. Analysing Policy: Whats the Problem Represented to be. Frenchs Forest, NSW: Pearson Education.

Baum, F.E., P. Laris, M. Fisher, L. Newman, and C. Macdougall. 2013. "Never mind the logic, give me the numbers": Former Australian health ministers' perspectives on the social determinants of health. Social Science \& Medicine 87: 138-146.

Blackman, T., E. Elliott, A. Greene, B. Harrington, D. Hunter, L. Marks, L. McKee, K. Smith, and G. Williams. 2009. Tackling health inequalities in post-devolution Britain: Do targets matter? Public Administration 87 (4): 762-778.

Blackman, T., B. Harrington, E. Elliott, A. Greene, D.J. Hunter, L. Marks, L. McKee, and G. Williams. 2012. Framing health inequalities for local intervention: Comparative case studies. Sociology of Health \& Illness 34 (1): 49-63.

Brassolotto, J., D. Raphael, and N. Baldeo. 2014. Epistemological barriers to addressing the social determinants of health among public health professionals in Ontario, Canada: A qualitative inquiry. Critical Public Health 24 (3): 321-336.

Dahlgren, G., and M. Whitehead. 2021. The Dahlgren-Whitehead model of health determinants: 30 Years on and still chasing rainbows. Public Health 199: 20-24.

Elias, N. 1978. What is Sociology? New York: Columbia University Press.

Exworthy, M., and V. Morcillo. 2019. Primary care doctors' understandings of and strategies to tackle health inequalities: A qualitative study. Primary Health Care Research \& Development 20 (e20): $1-7$.

Fairbrother, H., M. Crowder, C. Dodd-Reynolds, M. Egan, V. Er, E. Goyder, N. Griffin, E. Holding, K. Lock, and S. Scott. 2021. Exploring young people's perspectives of inequalities in health: A qualitative study. European Journal of Public Health 31 (Supplement_3): 5ckab165.501.

France, E.F., M. Cunningham, N. Ring, I. Uny, E.A. Duncan, R.G. Jepson, M. Maxwell, R.J. Roberts, R.L. Turley, and A. Booth. 2019a. Improving reporting of meta-ethnography: The eMERGe reporting guidance. BMC Medical Research Methodology 19: 25.

France, E.F., I. Uny, N. Ring, R.L. Turley, M. Maxwell, E.A. Duncan, R.G. Jepson, R.J. Roberts, and J. Noyes. 2019b. A methodological systematic review of meta-ethnography conduct to articulate the complex analytical phases. BMC Medical Research Methodology 19: 35.

Galvin, R. 2002. Disturbing notions of chronic illness and individual responsibility: Towards a genealogy of morals. Health: An Interdisciplinary Journal for the Social Study of Health, Illness and Medicine 6 (2): 107-137.

Gruen, R.L., S.D. Pearson, and T.A. Brennan. 2004. Physician-citizens-public roles and professional obligations. Journal of American Medical Association 291 (1): 94-98.

Hankivsky, O., and A. Christoffersen. 2008. Intersectionality and the determinants of health: A Canadian perspective. Critical Public Health 18 (3): 271-283.

Holt, D.H., K.L. Frohlich, T. Tjørnhøj-Thomsen, and C. Clavier. 2017. Intersectoriality in Danish municipalities: Corrupting the social determinants of health? Health Promotion International 32 (5): 881-890.

Javanparast, S., T. Freeman, F. Baum, R. Labonte, A. Ziersch, T. Mackean, R. Reed, and D. Sanders. 2018. How institutional forces, ideas and actors shaped population health planning in Australian regional primary health care organisations. BMC Public Health 18: 383.

Krieger, N., D. Dorling, and G. McCartney. 2012. Mapping injustice, visualizing equity: Why theory, metaphors and images matter in tackling inequalities. Public Health 126 (3): 256-258.

Lundberg, O. 2020. Next steps in the development of the social determinants of health approach: The need for a new narrative. Scandinavian Journal of Public Health 48 (5): 473-479. 
Lundell, H.C., J. Niederdeppe, and C.E. Clarke. 2013. Exploring interpretation of complexity and typicality in narratives and statistical images about the social determinants of health. Health Communication 28 (5): 486-498.

Lynch, J. 2017. Reframing inequality? The health inequalities turn as a dangerous frame shift. Journal of Public Health 39 (4): 653-660.

Mackenzie, M., A. Hastings, B. Babbel, S. Simpson, and G. Watt. 2017. Tackling and mitigating health inequalities-Policymakers and practitioners "talk and draw" their theories. Social Policy \& Administration 51 (1): 151-170.

Malpass, A., A. Shaw, D. Sharp, F. Walter, G. Feder, M. Ridd, and D. Kessler. 2009. "Medication career" or "moral career"? The two sides of managing antidepressants: A meta-ethnography of patients' experience of antidepressants. Social Science \& Medicine 68 (1): 154-168.

Marmot, M., J. Allen, T. Boyce, P. Goldblatt, and J. Morrison. 2020. Health Equity in England: The Marmot Review 10 Years On. London: Institute of Health Equity.

Marmot, M., J. Allen, P. Goldblatt, E. Herd, and J. Morrison. 2020. Build Back Fairer: The COVID19 Marmot Review. The Pandemic, Socioeconomic and Health Inequalities in England. London: Institute of Health Equity.

Marmot, M., S. Friel, R. Bell, T.A. Houweling, and S. Taylor. 2008. Closing the gap in a generation: Health equity through action on the social determinants of health. The Lancet 372 (9650): 1661-1669.

McIntyre, L., R. Shyleyko, C. Nicholson, H. Beanlands, and L. McLaren. 2013. Perceptions of the social determinants of health by two groups more and less affiliated with public health in Canada. BMC Research Notes 6: 247.

Mead, R., M. Thurston, and D. Bloyce. 2020. From public issues to personal troubles: Individualising social inequalities in health within local public health partnerships. Critical Public Health. https://doi.org/10.1080/09581596.2020.1763916.

Metzl, J.M., and H. Hansen. 2014. Structural competency: Theorizing a new medical engagement with stigma and inequality. Social Science \& Medicine 103: 126-133.

National Health Service. 2019. The NHS Long Term Plan. England: National Health Service.

Noblit, G.W., and R.D. Hare. 1988. Meta-Ethnography: Synthesizing Qualitative Studies. London: Sage.

Orton, L.C., F. Lloyd-Williams, D.C. Taylor-Robinson, M. Moonan, M. O'Flaherty, and S. Capewell. 2011. Prioritising public health: A qualitative study of decision making to reduce health inequalities. BMC Public Health 11: 821.

Pauly, B.M., S.Z. Shahram, P.T.H. Dang, L. Marcellus, and M. MacDonald. 2017. Health equity talk: Understandings of health equity among health leaders. AIMS Public Health 4 (5): 490-512.

Qureshi, K. 2013. It's not just pills and potions? Depoliticising health inequalities policy in England. Anthropology \& Medicine 20 (1): 1-12.

Raphael, D. 2011. A discourse analysis of the social determinants of health. Critical Public Health 21 (2): 221-236.

Raphael, D., and J. Brassolotto. 2015. Understanding action on the social determinants of health: A critical realist analysis of in-depth interviews with staff of nine Ontario public health units. $B M C$ Research Notes 8: 105.

Smith, K. 2013. Institutional filters: The translation and re-circulation of ideas about health inequalities within policy. Policy \& Politics 41 (1): 81-100.

Smith, K.E. 2014. The politics of ideas: The complex interplay of health inequalities research and policy. Science and Public Policy 41 (5): 561-574.

Smith, K.E., and R. Anderson. 2017. Understanding lay perspectives on socioeconomic health inequalities in Britain: A meta-ethnography. Sociology of Health \& Illness 40 (1): 146-170.

Smith, K.E., A. Macintyre, S. Weakley, S.E. Hill, O. Escobar, and G. Fergie. 2021. Public understandings of potential policy responses to health inequalities: Evidence from a UK national survey and citizens' juries in three UK cities. Social Science \& Medicine 291: 114458.

Spiegel, J.M., J. Breilh, and A. Yassi. 2015. Why language matters: Insights and challenges in applying a social determination of health approach in a North-South collaborative research program. Global Health 11: 9.

The King's Fund. 2021. Integrated care systems explained: making sense of systems, places and neighbourhoods [Online]. Available: https://www.kingsfund.org.uk/publications/integrated-caresystems-explained. Accessed August 3rd 2021. 
Thorne, S., L. Jensen, M.H. Kearney, G. Noblit, and M. Sandelowski. 2004. Qualitative metasynthesis: Reflections on methodological orientation and ideological agenda. Qualitative Health Research 14 (10): 1342-1365.

Tiles, M. 1984. Bachelard: Science and Objectivity. Cambridge: Cambridge University Press.

Warwick-Giles, L., A. Coleman, and K. Checkland. 2017. Making sense of Inequalities: How do clinical commissioning groups in England understand their new role? Social Policy \& Administration 51 (7): 1231-1247.

Weick, K.E. 1995. Sensemaking in Organizations. London: Sage.

Whitehead, M., and G. Dahlgren. 2006. Concepts and Principles for Tackling Social Inequities in Health: Levelling Up Part 1. Copenhagen, Denmark: World Health Organization Regional Office for Europe.

Willig, C. 2013. Foucauldian Discourse Analysis. Introducing Qualitative Research in Psychology, 3rd ed. London: McGraw-Hill Education.

Yates-Doerr, E. 2020. Reworking the social determinants of health: Responding to material-semiotic indeterminacy in public health interventions. Medical Anthropology Quarterly 34 (3): 378-397.

Publisher's Note Springer Nature remains neutral with regard to jurisdictional claims in published maps and institutional affiliations.

Naoimh E. McMahon is a Postdoctoral Launching Fellow in the National Institute for Health Research School for Public Health Research (NIHR SPHR) at Lancaster University. Naoimh first trained clinically as a physiotherapist before working in stroke research, and more recently moving into public health research with a specific focus on social inequalities in health. Her research explores the role of language and discourse in shaping how different actors come to understand inequalities in health, and the consequent implications for action. 